\title{
The Life Cycle and Growth Kinetics of an Anaerobic Rumen Fungus
}

\author{
By SUSAN E. LOWE, ${ }^{*}+$ GARETH G. GRIFFITH, ${ }^{2}$ ANDREW MILNE, 1 \\ MICHAEL K. THEODOROU ${ }^{3}$ AND ANTHONY P. J. TRINCI ${ }^{1}$ \\ ${ }^{1}$ Microbiology Group, Department of Cell and Structural Biology, School of Biological Sciences, \\ Williamson Building, University of Manchester, Manchester M13 9PL, UK \\ 2 Department of Botany and Microbiology, University College of Wales, \\ Aberystwyth, Dyfed SY23 3DA, UK \\ ${ }^{3}$ The Animal and Grassland Research Institute, Hurley, Maidenhead, Berkshire SL6 5LR, UK
}

(Received 4 November 1986; revised 5 March 1987)

The life cycle of an anaerobic fungus isolated from the rumen of sheep was studied and was found to be similar to that of the chytrids. The organism was monocentric. At $39^{\circ} \mathrm{C}$ the duration of the life cycle varied from about 26 to $32 \mathrm{~h}$. The zoospores were spherical or oval in shape and were polyflagellate ( 8 to 17 flagella per zoospore). During the first $6.5 \mathrm{~h}$ of growth there was a rapid development of an extensive, non-septate, highly branched rhizoidal system; during this period the 'main' rhizoid increased in length exponentially with a doubling time of $2.49 \mathrm{~h}$. Between 6.5 to $9.5 \mathrm{~h}$ after inoculation, the rate of extension of the main rhizoid declined, and no further extension occurred after $9.5 \mathrm{~h}$. The main rhizoid increased in width at its base from 2.2 to $15.0 \mu \mathrm{m}$ during the first $13 \mathrm{~h}$ after inoculation, indicating that intercalary wall growth occurred. Nuclei were occasionally observed in the rhizomycelium using DAPI (4',6-diamidino-2phenylindole) staining. Zoosporangia varied in shape from spherical to columnar, and some columnar zoosporangia were observed to become spherical. The zoosporangium initially increased in volume at an exponential rate with a doubling time of $1.56 \mathrm{~h}$. Between 14 to $20 \mathrm{~h}$ after inoculation, growth of the zoosporangium decelerated and little growth occurred after $20 \mathrm{~h}$ : the zoosporangium had a final volume of $2.5 \times 10^{5} \mu \mathrm{m}^{3}$. At about $21 \mathrm{~h}$ after inoculation, a septum was formed at the base of the zoosporangium, delimiting it from the rhizoidal system. The formation of this septum was correlated with the cessation of zoosporangial growth and the onset of zoosporogenesis. After zoosporogenesis, zoospores (about 88 zoospores per zoosporangium) were liberated through a pore formed in the zoosporangial wall opposite the main rhizoid. About $3 \mathrm{~h}$ after zoospore release the rhizoidal system became less refractile, suggesting that autolysis had occurred. Growth of the isolate was inhibited by nikkomycin (an inhibitor of chitin synthase), but not by amphotericin B or nystatin (antibiotics which bind to sterols).

\section{INTRODUCTION}

In 1912 Weissenberg described Callimastix cyclopis as a unicellular, polyflagellate protozoan parasite of Cyclops strenuus. Braune (1913) discovered a similar organism in the rumen of sheep and cattle which he named Callimastix frontalis. The suggestion of Weissenberg (1950) that $C$. cyclopis might be a zoospore of an aquatic fungus was borne out when the ultrastructure of $C$. cyclopis was studied by Vavra \& Joyon (1966) and when a plasmodial phase was identified in the body cavity of infected hosts; these workers concluded that $C$. cyclopis was related to the chytrid fungi and therefore the genus Callimastix with $C$. cyclopis as type species, was placed in the Blastocladiales. However, since the other species of Callimastix were still thought to be flagellate

† Present address: 410 Biochemistry Building, Michigan State University, East Lansing, Michigan 48827, USA.

Abbreviation: DAPI, 4',6-diamidino-2-phenylindole. 
protozoa they were placed in a new genus, Neocallimastix, with Neocallimastix frontalis (formerly C. frontalis) as the type species.

In 1975, Orpin reported that the life cycle of $N$. frontalis consisted of two phases, a non-motile reproductive stage and a motile flagellate stage. The discovery of a non-motile stage of $N$. frontalis led to the suggestion that the 'flagellates' were zoospores of an aquatic fungus. However, unlike zoospores of other aquatic fungi, which have one or two flagella per zoospore (Sparrow, 1960 ), zoospores of $N$. frontalis have up to 14 flagella per zoospore. Nevertheless, $N$. frontalis had a life cycle which was very similar to that of the chytrids.

Bauchop \& Mountfort (1981) isolated an anaerobic rumen fungus (PN1) which was similar to $N$. frontalis. After studies of its life cycle by light and electron microscopy, PN1 was officially described as $N$. frontalis (Heath et al., 1983). As the existing taxonomy of chytrids excluded organisms with polyflagellate zoospores (Sparrow, 1960) and because the organism was an anaerobe, Heath et al. (1983) placed $N$. frontalis in a new family, the Neocallimasticaceae, which was assigned to the order Spizellomycetales, in the class Chytridiomycetes. It was subsequently found that PN1 was not the same organism as the $N$. frontalis isolated by Orpin (1975) and therefore the latter organism was re-named $N$. patriciarum (Orpin \& Munn, 1986).

In this paper we describe the life cycle of an anaerobic rumen fungus similar to $N$. frontalis and $N$. patriciarum, which was isolated from sheep. Development of the organism was studied in liquid and agar media and the life cycle of the present isolate is compared with $N$. frontalis, $N$. patriciarum and other chytrid fungi. The life cycle of the organism is also considered in relation to the ecological niche which it may occupy in the rumen.

\section{METHODS}

Organism. The anaerobic fungus studied is a member of the genus Neocallimastix (Heath et al., 1983) which was isolated from sheep at the Animal and Grassland Research Institute, Hurley. The methods of fungal enrichment and isolation and a brief description of the fungal culture were the subject of a previous publication (Lowe $e t$ al., 1985). Since the original communication, the culture has been maintained on straw in a defined, liquid medium as described below. In order to ensure that the culture consisted of only a single fungus, culture supernatant, which contained zoospores, was serially diluted and used to inoculate roll tubes (Hungate, 1969) of molten defined medium B agar (modified from Lowe et al., 1985; see below). The tubes were incubated at $39^{\circ} \mathrm{C}$ for $2 \mathrm{~d}$ and, after examination with a Leitz Diavert inverted microscope, a tube containing a few colonies (each of which had developed from a single zoospore) was selected, and an individual colony was picked and transferred (using a sterile dissection needle) to an anaerobic culture tube $(18 \times 142 \mathrm{~mm}$, Bellco Glass) containing $10 \mathrm{ml}$ liquid defined medium B plus $25 \mathrm{~mm}$-glucose. All subsequent cultures were derived from this isolate, which has been designated R1. We have decided not to name the organism at the present time because direct comparisons with other members of the genus have not been made and the evidence presented in this paper and in Lowe et al. (1987b) suggests that Rl may be a new species.

Culture conditions. The anaerobic techniques used were as described by Hungate (1969), Bryant (1972) and Miller \& Wolin (1974). Defined medium B is the medium B described by Lowe et al. (1985), except that coenzyme $M$ solution, Trypticase peptone, yeast extract and antibiotics were omitted. Unless stated otherwise, the medium contained $25 \mathrm{~mm}$-glucose.

Stock cultures were maintained on $0.1 \mathrm{~g}$ wheat-straw (milled to pass through a $1 \mathrm{~mm}$ dry mesh screen) in $10 \mathrm{ml}$ defined medium $B$ and were inoculated with $1 \mathrm{ml}$ culture supernatant (containing zoospores); subcultures were made every $7 \mathrm{~d}$. Experimental cultures were inoculated with $1 \mathrm{ml}$ culture supernatant from cultures grown for $3 \mathrm{~d}$ on defined medium B; these were in the late-exponential phase of growth and haemocytometer counts showed that they contained about $1 \times 10^{3}$ zoospores $\mathrm{ml}^{-1}$. All cultures were transferred using anaerobic pipetting techniques and, unless stated otherwise, they were incubated at $39^{\circ} \mathrm{C}$ under a gas phase of $100 \% \mathrm{CO}_{2}$ without agitation. The light microscope was used routinely to ensure that cultures were free from bacterial contamination.

Morphological observations. Development of the fungus was followed in agar medium in roll tubes, on coverslips or membrane filters in liquid medium, and on cellophane strips in liquid medium. Roll tubes were prepared using defined medium $B$ and $1.8 \%(w / v)$ agar. To ensure that only a few colonies developed in each culture, tubes containing $3 \mathrm{ml}$ molten defined medium B agar were inoculated with $1 \mathrm{ml}$ culture supernatant which had been diluted with defined medium B until it contained approximately 10 zoospores $\mathrm{ml}^{-1}$.

Cellophane (British Cellophane) strips $(3 \times 5 \mathrm{~cm})$ were washed by boiling in distilled water for $10 \mathrm{~min}$ and placed around the inside of anaerobic tubes (one strip per tube). After autoclaving, $10 \mathrm{ml}$ defined medium $B$ lacking glucose was added and each tube was inoculated with $1 \mathrm{ml}$ zoospore suspension; cellophane was the carbon source in these cultures. 
Development of the isolate in roll tubes and in 'cellophane' cultures was observed using an inverted microscope housed in a perspex incubator maintained at 37 to $39^{\circ} \mathrm{C}$. Cultures were incubated on the microscope stage to allow continuous microscopic observation and photographs were taken using FP4 ASA 125 black and white film (Ilford).

Development of the isolate was also followed on glass coverslips and on membrane filters $(0.22 \mu \mathrm{m}$ pore size, Metricel Membrane Filters; Gelman Sciences) added to liquid defined medium B in anaerobic tubes. The use of coverslips to observe aquatic fungi has been described by Fuller (1962) and it proved a useful technique in studying the $\mathrm{R} 1$ isolate, which encysted on glass and adhered to it during subsequent growth. Circular (12 mm diameter) glass coverslips (Chance Propper) were cleaned with alcohol and autoclaved in anaerobic culture tubes, prior to the addition of $10 \mathrm{ml}$ defined medium $B$. The tubes were inoculated with $1 \mathrm{ml}$ undiluted or diluted culture supernatant; dilutions were made using defined medium B lacking glucose. Growth was stopped by addition of $1 \mathrm{ml} 25 \%(\mathrm{v} / \mathrm{v})$ glutaraldehyde solution. After $10 \mathrm{~min}$ at room temperature, the coverslips were mounted in $0.2 \mathrm{M}$ phosphate buffer ( $\mathrm{pH} 7.2)$ and examined using a Reichert microscope. All microscopic measurements were made using a travelling micrometer eye piece (C. Baker).

Coverslip cultures were also used to examine the effects of antibiotics on growth. Nikkomycin (kindly supplied by Professor G. Gooday), amphotericin B [dissolved in $35 \%(\mathrm{w} / \mathrm{v})$ sodium deoxycholate] or nystatin were included in the medium prior to inoculation, or were added to growing cultures $12 \mathrm{~h}$ after inoculation. An appropriate concentration of sodium deoxycholate was included in the medium of cultures used as controls for the amphotericin B treatments.

DAPI staining. Nuclei fluoresce when stained with the fluorochrome DAPI (4',6-diamidino-2-phenylindole) and illuminated with UV light (Hooley et al., 1982). The stain solution contained 0.3 g DAPI (Sigma) per litre of $0.05 \mathrm{M}-\mathrm{Tris} / \mathrm{HCl}$ buffer ( $\mathrm{pH} 7 \cdot 2$ ), containing $100 \mathrm{mM}-\mathrm{NaCl}$ and $10 \mathrm{~mm}$-EDTA. Coverslips removed from growing cultures were placed on a slide with a drop of the stain and left at room temperature in the dark for 10 min before being examined. A Zeiss transmitted-light photomicroscope III fitted with an exciter filter (G 365), a barrier filter (LP 418) and Neofluar objectives were used to observe the nuclei. Photographs were taken using FP4 ASA 1000 film.

Cryo-scanning electron microscopy (cryo-SEM). Cultures growing on membrane filters were used. Frozen, hydrated material was prepared for cryo-SEM in a similar manner to that described by Webb \& Jackson (1986). Membranes (cut to $3 \mathrm{~mm}$ square) were removed from the culture medium, rinsed quickly in distilled water and blotted almost dry on filter paper. These were then attached to the specimen stub with carbon cement, frozen rapidly in nitrogen slush and transferred, under vacuum, to the cooled prechamber of a Hexland CT1000 cryotransfer system which was interphased to a Philips 505 scanning electron microscope. Excess water was sublimed away by heating to about $-90^{\circ} \mathrm{C}$ and the specimen was cooled to about $-160^{\circ} \mathrm{C}$ and sputter-coated with gold. Coated specimens were viewed by SEM at about $-180^{\circ} \mathrm{C}$.

\section{RESULTS}

The zoospores

The uninucleate zoospores were usually spherical (Fig. $1 a$ ) to ovoid and measured $10.71 \pm 1.79 \mu \mathrm{m} \times 9.64 \pm 1.88 \mu \mathrm{m}$ (mean \pm standard error, $n=30$ ). Between 8 and 17 flagella were present on each zoospore and each flagellum was several times longer than the zoospore. During motility, the flagella united to form a single locomotory organelle. Zoospores moved in an erratic manner, sometimes swimming in a circular motion or moving with a rapid darting motion, interrupted by frequent pauses and changes in direction. Zoospores were occasionally observed to move in an amoeboid manner and during these periods the flagella sometimes separated from one another and spherical bodies were occasionally observed on their tips (Fig. $1 \mathrm{~b}$ ). Some zoospores remained motile for a number of hours but others encysted within a matter of minutes of their release fom zoosporangia. Encystment of a zoospore was rapidly followed by the formation of a main (germination) rhizoid. Flagella remained attached to the zoospore after encystment but occasionally young plants (rhizoids plus immature zoosporangium) were observed which lacked flagella.

\section{Rhizoid and zoosporangium development}

Studies were made of the development of a single plant in a roll tube (Figs 2, 3 and $4 a$ ) and of a population of plants on coverslips in liquid culture (Figs 3 and $4 b$ ). At the outset the encysted zoospore in the roll tube culture was $12.0 \mu \mathrm{m}$ long and $10.4 \mu \mathrm{m}$ wide (Fig. $4 a$ ). During the first $6.5 \mathrm{~h}$ after inoculation there was a rapid development of an extensive rhizoidal system (Figs 2 

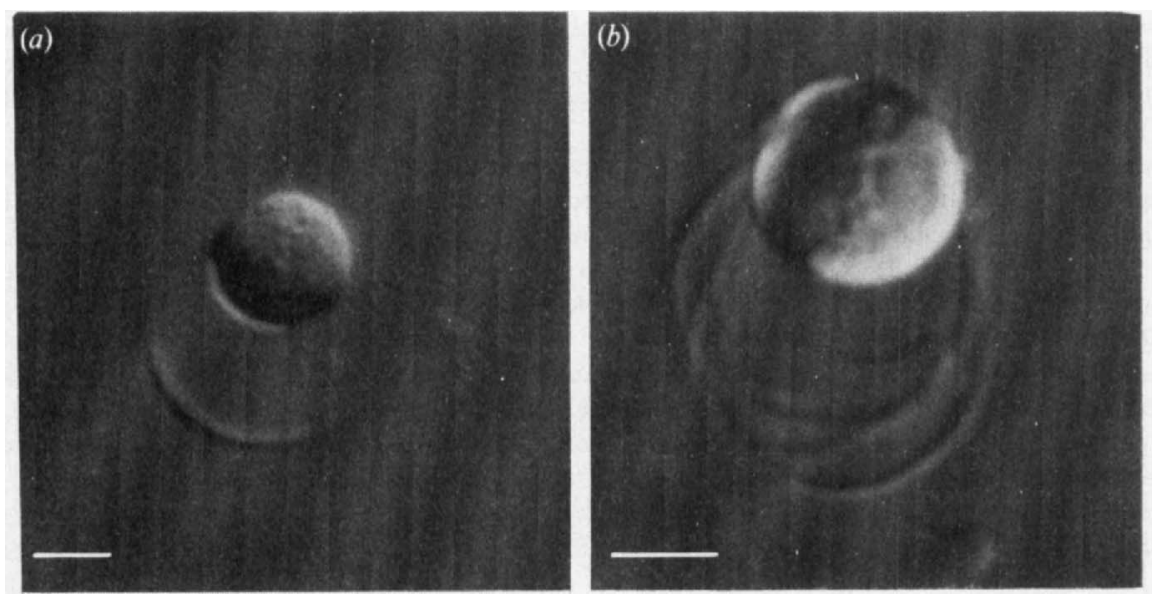

Fig. 1. (a) A zoospore of Rl with a single aggregate of flagella; (b) a zoospore with separated flagella and spherical bodies associated with the tips. Bars, $5 \mu \mathrm{m}$.

and 3); during this period the main rhizoid increased in length exponentially with a doubling time of $2.49 \mathrm{~h}$ (specific growth rate $=0.28 \mathrm{~h}^{-1}$ ). Between 6.5 to $9.5 \mathrm{~h}$ after inoculation, there was a deceleration in the rate of extension of the main rhizoid, and no further extension occurred after $9.5 \mathrm{~h}$, at which time the rhizoid was $734 \mu \mathrm{m}$ long. Growth of the main rhizoid provided a convenient indicator of the growth of the whole rhizoidal system (Fig. $2 a-d$ ).

The zoosporangium initially increased in volume at an exponential rate (Fig. $4 a$ ) with a doubling time of $1.56 \mathrm{~h}$ (specific growth rate $=0.44 \mathrm{~h}^{-1}$ ). Between 14 to $20 \mathrm{~h}$ after inoculation, growth of the zoosporangium decelerated and little growth occurred after $20 \mathrm{~h}$. Cessation of zoosporangial growth was correlated with the formation of a septum at the base of the zoosporangium; observations of a number of plants showed that septum formation occurred $21.3 \pm 1.00 \mathrm{~h}$ after inoculation. The zoosporangium in Fig. 4(a) had a final volume of $2.5 \times 10^{5} \mu \mathrm{m}^{3}$.

Zoospores were liberated from the zoosporangium $27 \mathrm{~h}$ after inoculation, but instead of swimming away, they encysted in the agar medium at the site of the parent zoosporangium (Fig. $2 e$ ). Each encysted zoospore rapidly developed its own rhizoidal system and these rhizoids grew radially away from the central area of developing plants (Fig. $2 f$ ). Extension of rhizoids of the second generation of plants continued, and $3 \mathrm{~h}$ after the zoospores had been released, the rhizoidal system of the parent plant became less refractile. Development of the second generation of zoospores into mature plants was followed by the liberation of a third generation of zoospores and these swam away from the parent zoosporangia to encyst and germinate at the outer edge of the region of rhizoidal growth.

Development of the R1 isolate on coverslips in liquid cultures was also studied. Growth of zoosporangia which developed on coverslips in liquid culture was similar to that observed for the zoosporangium which developed in the agar roll tube (Fig. $4 a, b$ ). The most significant change in size of the population of zoosporangia occurred 12 to $26 \mathrm{~h}$ after inoculation during the latter part of the life cycle. During this period the developing zoosporangia became 'ovoid' and $26 \mathrm{~h}$ after inoculation they had a mean size of $103.3 \pm 5.70 \times 81.5 \pm 6.01 \mu \mathrm{m}(n=18)$ (Fig. $4 b)$. These mean measurements suggest that the zoosporangia were all ovoid in shape. However, the population contained both spherical $(120 \times 120 \mu \mathrm{m})$ and columnar $(140 \times 62 \mu \mathrm{m})$ zoosporangia. Direct observations of growing cultures showed that the shape of a zoosporangium sometimes changed during its development. Most zoosporangia were initially spherical, but subsequent development sometimes resulted in the formation of columnar zoosporangia. Some columnar zoosporangia were also observed to change in shape, becoming spherical. When this happened the length of the zoosporangium remained approximately constant but its width increased. Cryo-scanning electron micrographs of individual plants of the $\mathrm{R} 1$ isolate, which were observed 

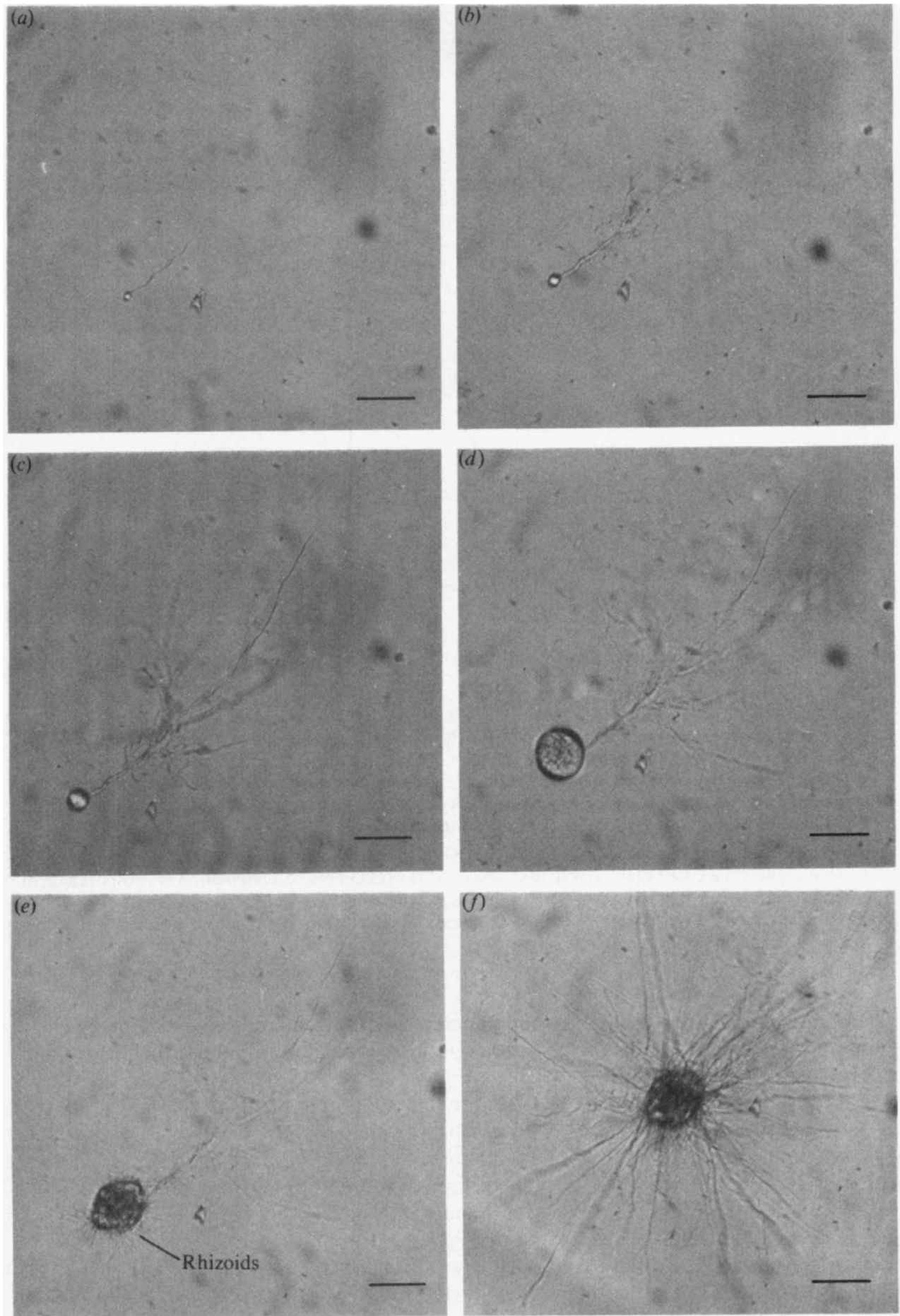

Fig. 2. Development of a single plant of R1 in a roll tube $(a) 1.5 \mathrm{~h},(b) 5.0 \mathrm{~h},(c) 9.0 \mathrm{~h}$ and $(d) 24 \mathrm{~h}$ after inoculation, and $(e) 0.5 \mathrm{~h}$ and $(f) 2.0 \mathrm{~h}$ after the onset of liberation of zoospores from the zoosporangium. Zoospores were liberated $27 \mathrm{~h}$ after inoculation. Bars, $100 \mu \mathrm{m}$. 


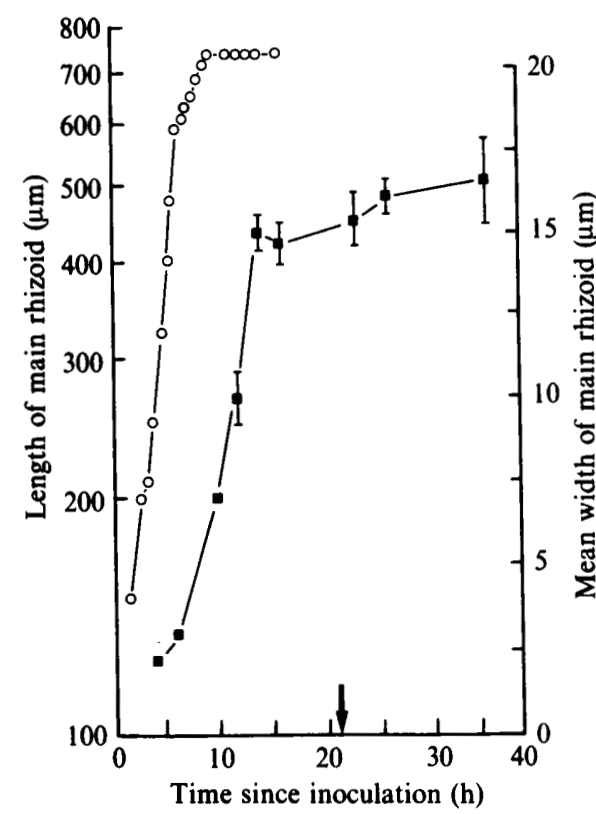

Fig. 3

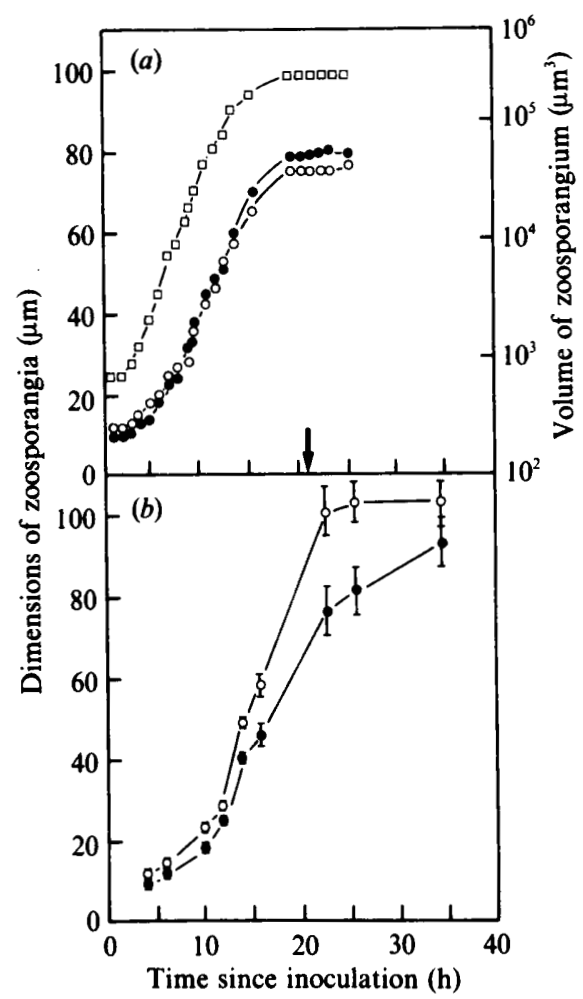

Fig. 4

Fig. 3. Development of the main rhizoid of $R 1$ in roll tube and coverslip cultures. $O$, Length of the main rhizoid of a single plant growing in a roll tube; $\square$, mean width of the main rhizoid of a population of plants growing on coverslips in liquid medium (measurements were made of the width of the rhizoid immediately below the developing zoosporangium: error bars represent SE of the mean where $n=18$ ). The arrow indicates time $( \pm 1.00 \mathrm{~h})$ of septum formation.

Fig. 4. Development of zoosporangia of $\mathrm{R} 1$ in roll tube and coverslip cultures. (a) Development of a zoosporangium of a single plant in roll tube culture; $(b)$ development of a population of zoosporangia in coverslip culture (error bars represent SE of the mean where $n=18$ ). Zoosporangial length $(O)$, width $(\bigcirc)$ and volume $(\square)$ were determined. Volume was calculated from the relationship $\frac{4}{3} \pi r^{3}$. The arrow indicates time $( \pm 1.00 \mathrm{~h})$ of septum formation.

on membrane filters after $48 \mathrm{~h}$ incubation in defined medium B, are shown in Fig. 5. The main rhizoid and range of shapes of the zoosporangia were typical morphological characteristics of the Rl isolate (Fig. 5).

Although the length of the main rhizoid of the population of plants developing on coverslips was not determined, the width of the rhizoid immediately beneath the base of the zoosporangium was measured (Fig. 3). Four hours after inoculation the main rhizoid had a mean width of $2 \cdot 2 \pm 0.11 \mu \mathrm{m}(n=18)$. Subsequent growth resulted in an increase in width and $14 \mathrm{~h}$ after inoculation the main rhizoid had a mean width of $15.0 \pm 0.61 \mu \mathrm{m}(n=18)$. No further increase occurred during the rest of the life cycle.

Young zoosporangia initially contained one nucleus per zoosporangium (Fig. 6a, b), but mature zoosporangia contained very many nuclei (Fig. $6 c, d$ ). The presence of DAPI-staining bodies (presumably nuclei) within the main rhizoid was observed on a number of occasions and similar DAPI-staining structures were also observed in rhizoids distant from the zoosporangium.

The number of plants formed on coverslips recovered from liquid medium was determined to give an estimate of the length of the life cycle and the number of zoospores formed per 

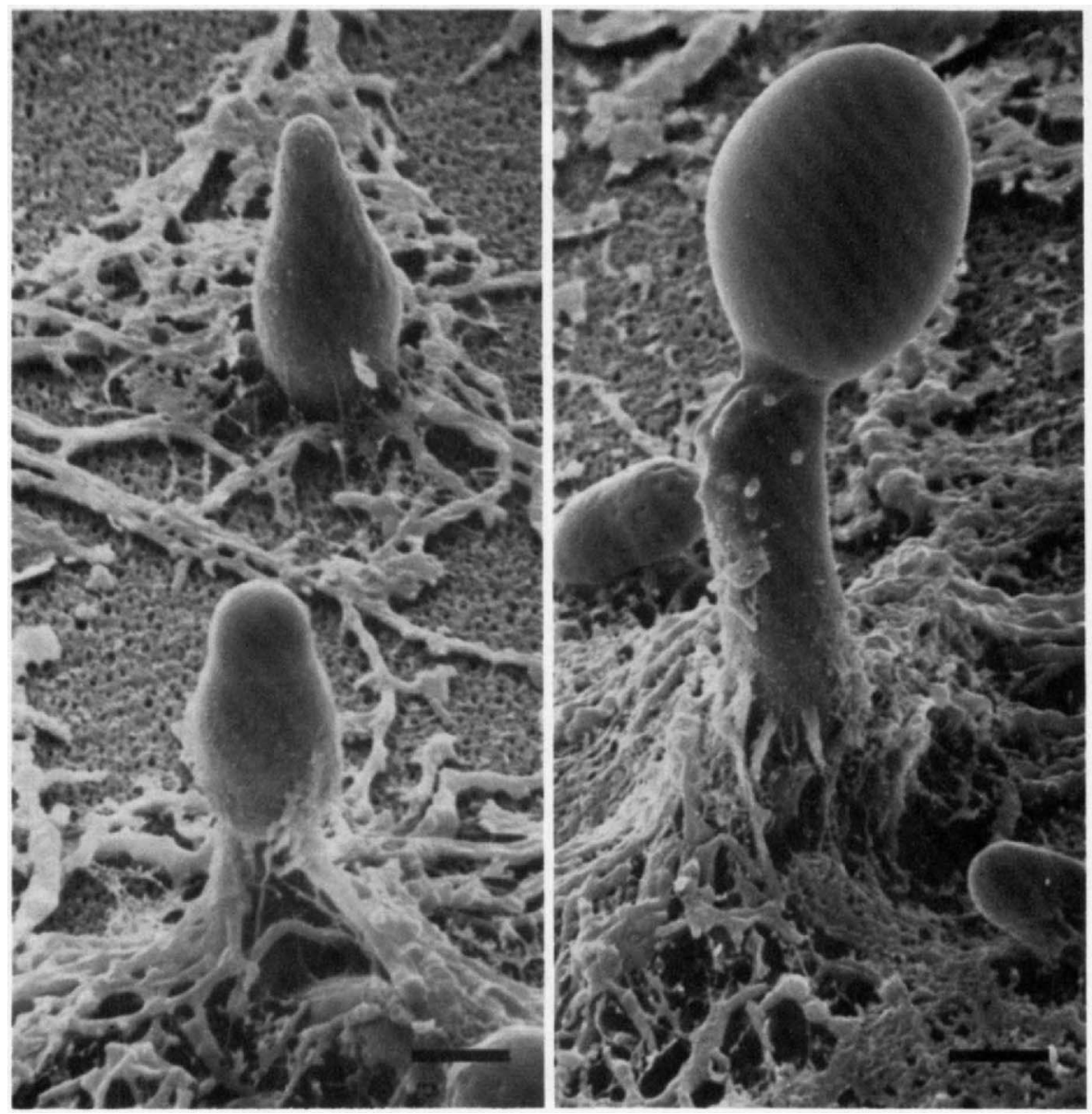

Fig. 5. Cryo-scanning electron micrographs of plants of $R 1$ on membrane filters after $48 \mathrm{~h}$ incubation in liquid medium. Bars, $10 \mu \mathrm{m}$.

zoosporangium (Fig. 7). In cultures with a high concentration of zoospores the number of plants formed per coverslip increased steadily with time. Two hours after inoculation a mean of 48 plants were attached to each coverslip, and after $26 \mathrm{~h}$ this had increased to 413 plants. By $29 \mathrm{~h}$ after inoculation there were too many plants present to count. These observations suggest that the mean duration of the life cycle under these conditions was between 26 and $29 \mathrm{~h}$.

Cultures inoculated with a dilute zoospore suspension had counts of 5 to 16 plants per coverslip during the first $29 \mathrm{~h}$ after inoculation (Fig. 7). The number of plants per coverslip did not increase appreciably until $32 \mathrm{~h}$ after inoculation, by which time 37 plants were present per coverslip. At $47 \mathrm{~h}$ after inoculation the mean number of plants per coverslip (782) indicated that zoospore release had occurred. From these data, it was calculated that about 88 zoospores were released from each zoosporangium. Fig. 7 suggests that the duration of the life cycle may be influenced by zoospore concentration and that low concentrations of zoospores may develop more synchronously than high concentrations of zoospores.

\section{Liberation of the zoospores}

Liberation of zoospores from a zoosporangium formed on cellophane in liquid medium is shown in Fig. 8. The release of zoospores from zoosporangia has been observed on several occasions and the position of the exit point was always the same, viz. a pore in the zoosporangial wall formed opposite the main rhizoid. Some gyratory movement of the zoospores occurred 

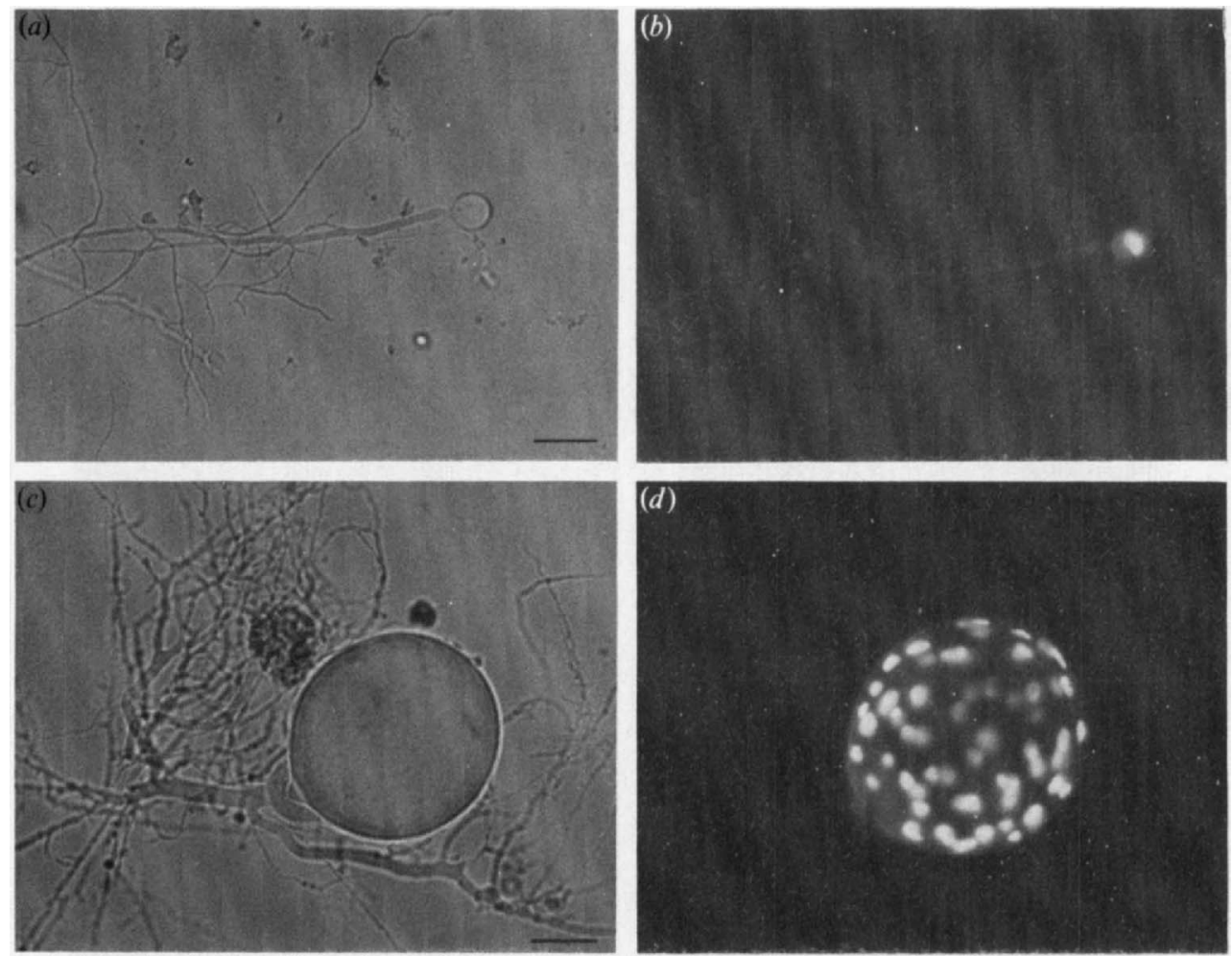

Fig. 6. (a) An immature zoosporangium of $\mathrm{R} 1$; (b) the same zoosporangium under fluorescence illumination showing a single DAPI-staining nucleus. (c) A mature zoosporangium of $\mathrm{R} 1 ;(d)$ the same zoosporangium under fluorescence illumination showing numerous DAPI-staining nuclei. Bars, $50 \mu \mathrm{m}$.

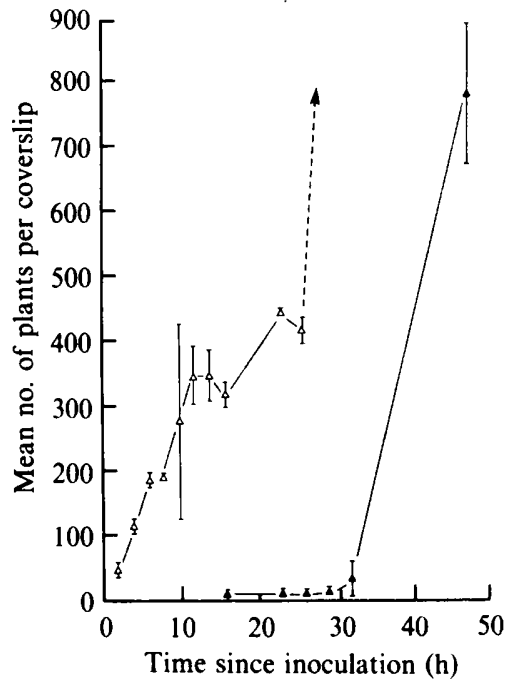

Fig. 7. Increase in the number of plants of $R 1$ on coverslips in liquid cultures. Coverslip-containing anaerobic tubes were inoculated with either $1 \mathrm{ml}$ culture supernatant $(\triangle)$, or $1 \mathrm{ml}$ culture supernatant diluted $1: 49(\boldsymbol{A})$. Five replicate cultures were sampled at each time interval. The error bars represent SE of the mean. 

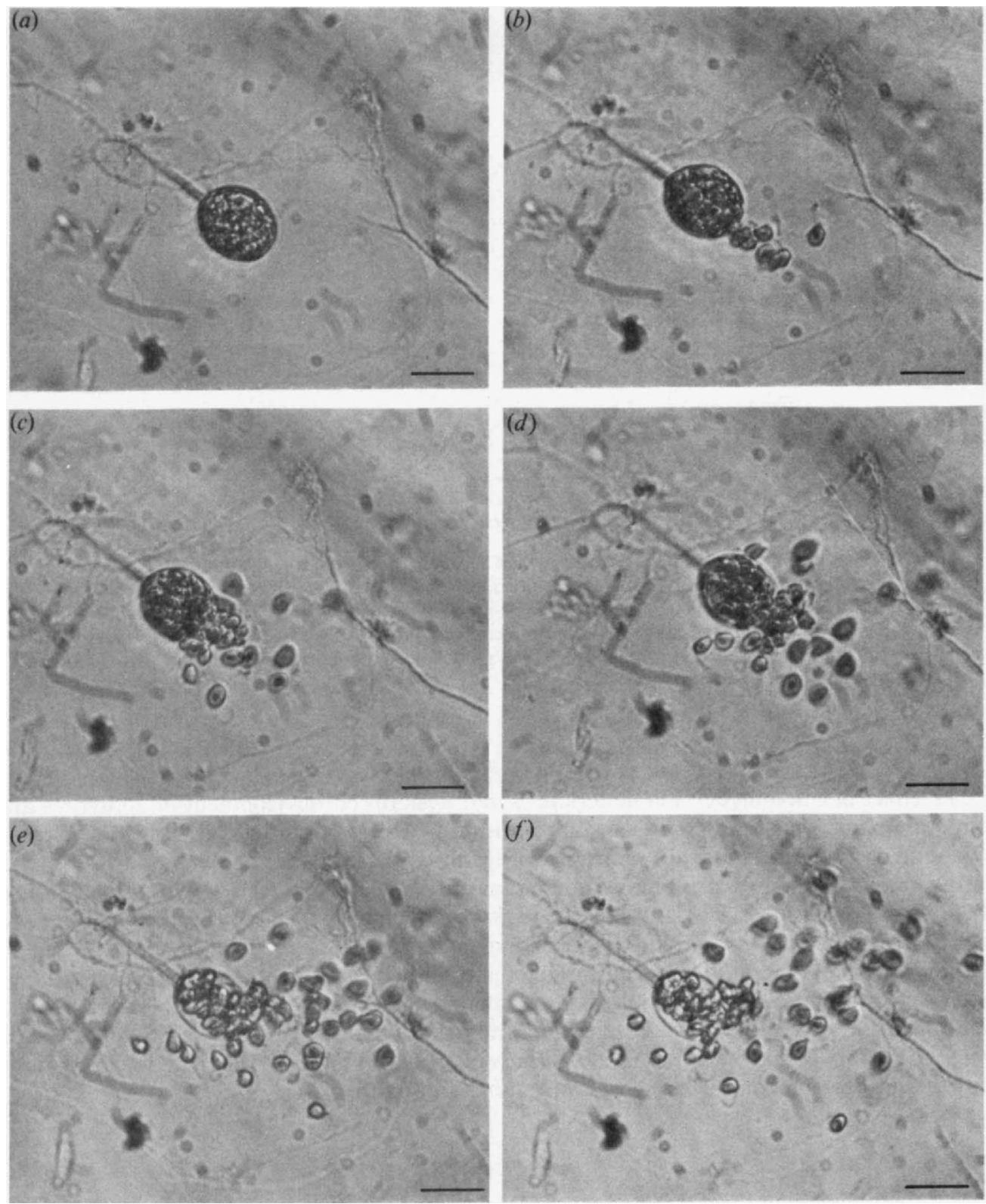

Fig. 8. Liberation of zoospores from a zoosporangium of R1. Observations were made of a culture growing on cellophane in liquid medium. (a) Zoosporangium with spherical bodies (developing zoospores) inside. (b) Zoospores leaving from a pore in the zoosporangium wall opposite the main rhizoid. $(c) 90 \mathrm{~s},(d) 120 \mathrm{~s},(e) 180 \mathrm{~s}$ and $(f) 210 \mathrm{~s}$ after the onset of zoospore release. Bars, $100 \mu \mathrm{m}$.

within the zoosporangium prior to their release, and this motion increased until eventually the zoospores were liberated. At this time some zoospores were abruptly shot out of the zoosporangium (Fig. $8 \mathrm{~b}$ ) and these began swimming in the medium. The remaining zoospores in the zoosporangium swam out through the pore and $3.5 \mathrm{~min}$ after the onset of dispersal, the zoosporangium contained only a few zoospores (Fig. 8ff). Once empty, the 'ghost' zoosporangium remained and eventually the rhizoidal system autolysed. 


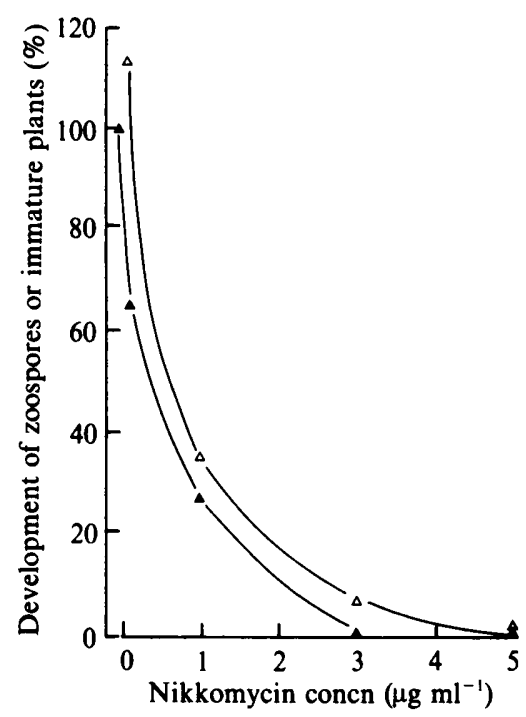

Fig. 9. Effect of nikkomycin on the development of zoospores and immature plants of R1. Nikkomycin was either present at the time of inoculation with zoospores $(\Delta)$, or was added to cultures (containing immature plants) $12 \mathrm{~h}$ after inoculation $(\triangle)$. The numbers of zoospores and immature plants which developed in the presence of nikkomycin were recorded $13 \mathrm{~h}$ and $36 \mathrm{~h}$ after inoculation respectively. The results are expressed as a percentage of the number of zoospores and immature plants which developed in cultures lacking antibiotics.

\section{Effect of antibiotics}

The effect of nikkomycin, amphotericin B and nystatin on development of zoospores and immature plants was examined. Nikkomycin is an inhibitor of chitin synthase (Muller et al., 1981) and was used to assess the importance of chitin synthase in development of the R1 isolate. Amphotericin B and nystatin bind to membrane sterols and inhibit the growth of many fungi (Medoff \& Kobayashi, 1980). The effect of nikkomycin on growth of R1 is shown in Fig. 9. At $0.1 \mu \mathrm{g} \mathrm{ml}^{-1}$ (final concentration) the development of immature plants was not affected by nikkomycin; however, at this concentration of antibiotic, only $65 \%$ of the zoospores developed into plants. Zoospores and immature plants incubated in the presence of $3 \mu \mathrm{g} \mathrm{ml}^{-1}$ and $5 \mu \mathrm{g} \mathrm{ml}^{-1}$ of nikkomycin respectively, did not develop into mature plants. Amphotericin B and nystatin were included in defined medium $B$ at concentrations up to $10 \mu \mathrm{g} \mathrm{ml}^{-1}$ but had no effect on the growth and development of zoospores and immature plants of R1.

\section{DISCUSSION}

The morphology and life cycle of the R1 isolate resembled that of eucarpic chytrids, and consisted of a reproductive body, the zoosporangium, supported by a filamentous, vegetative structure of branching, tapering rhizoids. The formation of a single zoosporangium is indicative of monocentric chytrids. The morphology of the $\mathrm{R} 1$ isolate resembles that of the chytrid Chytridium. In Chytridium the zoospore encysts and produces a main rhizoid which penetrates the substratum. The rhizoids continue to elongate and transport nutrients back to the encysted zoospore. Development of Chytridium is described as epibiotic because the zoosporangium is present on the surface of the substratum and the rhizoidal system grows within the plant material. During the later stages of development the zoosporangium becomes separated from the rhizoidal system by the formation of a septum at its base (Sparrow, 1960).

According to Waterhouse (1962) 'the swimming motion of zoospores may be extremely jerky and erratic, and interspersed with periods of dormancy'. The zoospores of the R1 isolate have been observed to behave in a similar manner, and during the pauses some zoospores underwent 
amoeboid changes in shape. This type of behaviour is characteristic of chytrid zoospores (Sparrow, 1960) and may be a prelude to encystment.

Observations of the life cycle of the $\mathbf{R} 1$ isolate showed that, after zoospore encystment, there was a period of rapid development of the rhizoidal system, with only a small increase in the size of the developing zoosporangium. This type of growth has also been observed by Bauchop $(1979 a, b, 1980,1981)$ in his studies on fungal colonization of feed material in the rumen. He observed extensive development of the rhizoidal system during the first $12 \mathrm{~h}$ of growth of the fungi on material in the rumen, and then the zoosporangium increased in size until the life cycle was completed. Septum formation in the Rl isolate occurred about $21 \mathrm{~h}$ after inoculation, towards the latter stages of the life cycle. Heath et al. (1983) also found that the onset of zoosporogenesis was correlated with septation. No pore was observed in the septum, which therefore formed a barrier to cytoplasmic flow from the rhizoidal system to the zoosporangium. After zoospore release, the zoosporangium and the rhizoidal system autolysed; this phenomenon has been reported for other chytrids (Sparrow, 1960).

The observation of DAPI-staining bodies (nuclei) within the rhizoids was unexpected. It is generally accepted that members of the Chytridiales produce a limited rhizoidal system, and the rhizoids possess cytoplasm but no nuclei. During development of the main rhizoid, intercalary wall growth occurred at the point where it joined the zoosporangium. It is not known if growth of the zoosporangium is autocatalytic or, as is more likely, supported at least in part by growth in the rhizoidal system. The observation that the zoosporangium had a faster specific growth rate $\left(0.44 \mathrm{~h}^{-1}\right)$ than the main rhizoid $\left(0.28 \mathrm{~h}^{-1}\right)$ supports the latter hypothesis.

Zoosporangia of the $\mathrm{Rl}$ isolate varied in shape from spherical to columnar. Similar observations have been made by Orpin (1975) and Orpin \& Munn (1986) in their studies of $N$. patriciarum. Variation in the shape and size of zoosporangia of other chytrids also occurs (Sparrow, 1960) and this is particularly true of Endochytrium operculatum (Karling, 1937), which forms both spherical and pyriform zoosporangia. Chytrids either form a single pore through which zoospores are discharged or several pores; the manner of zoospore release is characteristic for a particular species and all the zoospores released develop and release their zoospores in the same manner (Sparrow, 1960). Release of zoospores by the R1 isolate always occurred from a point in the zoosporangium wall opposite the main rhizoid. In this respect the RI isolate differed from $N$. frontalis (Heath et al., 1983) in which zoospore release occurred by 'nonlocalized dissolution of the entire zoosporangium wall'. Examination of photographs of zoospore release from a zoosporangium of $N$. patriciarum (Orpin, 1975) suggests that zoospores of this fungus were released from a number of pores in the zoosporangial wall. These differences in the methods of zoospore release between $\mathrm{R} 1, N$. frontalis and $N$. patriciarum suggest that they are different species.

Movement of zoospores within the zoosporangium prior to their release may act as a trigger for zoospore discharge (Sparrow, 1960). Our observations of zoospores leaving zoosporangia are typical of descriptions given by Sparrow for other chytrids in which the first zoospores to leave are ejected by force and the remainder leave the zoosporangium either by swimming or by amoeboid movement. The zoospores of the $\mathrm{R} 1$ isolate sometimes swam for several hours prior to encystment; Munn et al. (1981) have detected glycogen in zoospores of $N$. patriciarum and this could supply the source of energy needed for prolonged periods of swimming and for subsequent encystment and germination.

On average, about 88 zoospores were released per zoosporangium, but small zoosporangia have been observed to release fewer zoospores. Observations by Joblin (1981) on zoospore release from rumen fungi showed that between 10 and 120 viable zoospores were liberated per zoosporangium. With $N$. patriciarum between 2 and 38 zoospores were formed within zoosporangia (Orpin, 1975). Autolysis of the rhizoidal system after zoospore release suggests that each plant has a finite life span.

The effect of nikkomycin on growth of R1 suggests that chitin synthase is an important enzyme in this organism and that its walls contain chitin. Orpin (1977) has reported the presence of chitin in $N$. frontalis, Piromonas communis and Sphaeromonas communis, and Brownlee (1986) has recently demonstrated the presence of chitin synthase in anaerobic fungi. Analysis of $N$. 
frontalis (Body \& Bauchop, 1985) suggested that $12 \%$ of its lipids consisted of sterols. However, Kemp et al. (1984) failed to detect sterols in P. communis. Oxygen is essential for sterol synthesis (Goldfine \& Bloch, 1963), but anaerobic organisms may obtain these compounds from their environment. However, sterols do not seem to be essential for the growth of R1, as nystatin and amphotericin B, antibiotics that bind to membrane sterols and cause cell leakage, did not affect growth.

Rhizoids facilitate the attachment of rumen fungi to plant material, and such attachment would increase their residence time in the rumen. The main function of rhizoids is to absorb nutrients from the substrate, and their ability to penetrate and degrade plant tissues (Bauchop, 1980; Lowe et al., 1987 b) may allow these fungi to reach growth substrates not accessible to bacteria or protozoa. The production of extracellular cellulases and xylanase by rumen fungi (Mountfort \& Asher, 1985; Pearce \& Bauchop, 1985; Lowe et al., 1987a) enables them to utilize cellulose and hemicellulose as substrates for growth.

We would like to thank the Science and Engineering Research Council for the award of a CASE research studentship to S.E.L. and the Nuffield Foundation for supporting part of this research. We also thank $\mathrm{Mr}$ G. Grange (University of Manchester) and Miss J. A. Sumner (AGRI) for the photography and Mrs J. Webb (AGRI) for the electron microscopy. The Animal and Grassland Research Institute is financed through the Agricultural and Food Research Council.

\section{REFERENCES}

BAUCHOP, T. (1979a). The rumen anaerobic fungi: colonizers of plant fibre. Annales de recherches vétérinaires 10, 246-248.

BAUCHOP, T. (1979b). Rumen anaerobic fungi of cattle and sheep. Applied and Environmental Microbiology 38, 148-158.

BAUCHOP, T. (1980). Scanning electron microscopy in the study of microbial digestion of plant fragments in the gut. In Contemporary Microbial Ecology, pp. 305326. Edited by D. C. Ellwood, J. M. Hedger, M. J. Latham, J. M. Lynch \& J. H. Slater. London: Academic Press.

BAUCHOP, T. (1981). The anaerobic fungi in rumen fibre digestion. Agriculture and Environment 6, 339-348.

BAuChop, T. \& Mountfort, D. O. (1981). Cellulose fermentation by a rumen anaerobic fungus in both the absence and the presence of rumen methanogens. Applied and Environmental Microbiology 42, $1103-1110$.

BODY, D. R. \& BAUCHOP, T. (1985). Lipid composition of an obligately anaerobic fungus Neocallimastix frontalis isolated from a bovine rumen. Canadian Journal of Microbiology 31, 463-466.

BRAUNE, R. (1913). Untersuchungen über die im Wiederkauermagen vorkommenden Protozoen. Archiv für Protistenkunde 32, 111-170.

Brownlee, A. G. (1986). Properties of chitin synthetase from a rumen anaerobic fungus. In Abstracts of the XIV International Congress of Microbiology, p. 153.

Bryant, M. P. (1972). Commentary on the Hungate technique for culture of anaerobic bacteria. American Journal of Clinical Nutrition 25, 1324-1328.

FULLER, M. S. (1962). Growth and development of the water mold Rhizidiomyces in pure culture. American Journal of Botany 49, 64-71.

Goldfine, H. \& Bloch, K. (1963). Oxygen and biosynthetic reactions. In Control Mechanisms in
Respiration and Fermentation (8th Symposium of the Society for General Physiology), pp. 81-103. Edited by B. Wright. New York: Ronald Press.

Heath, I. B., Bauchop, T. \& SkIpp, R. A. (1983). Assignment of the rumen anaerobe Neocallimastix frontalis to the Spizellomycetales (Chytridiomycetes) on the basis of its polyflagellate zoospore ultrastructure. Canadian Journal of Botany 61, 295-307.

Hooley, P., Fyfe, A. M., Evola Maltese, C. \& Shaw, D. S. (1982). Duplication cycle in nuclei of germinating zoospores of Phytophthora drechsleri as revealed by DAPI staining. Transactions of the British Mycological Society 79, 563-566.

Hungate, R. E. (1969). A roll tube method for the cultivation of strict anaerobes. Methods in Microbiology 3B, 117-132.

Joblin, K. N. (1981). Isolation, enumeration, and maintenance of rumen anaerobic fungi in roll tubes. Applied and Environmental Microbiology 42, 11191122.

Karling, J. S. (1937). The structure, development, identity, and relationship of Endochytrium. American Journal of Botany 24, 352-364.

Kemp, P., LANDeR, D. J. \& ORPIN, C. G. (1984). The lipids of the rumen fungus Piromonas communis. Journal of General Microbiology 130, 27-37.

Lowe, S. E., Theodorou, M. K., Trinci, A. P. J. \& Hespell, R. B. (1985). Growth of anaerobic rumen fungi on defined and semi-defined media lacking rumen fluid. Journal of General Microbiology 131, 2225-2229.

Lowe, S. E., Theodorou, M. K. \& Trincl, A. P. J. $(1987 a)$. Cellulases and xylanase of an anaerobic rumen fungus grown on wheat-straw lignocellulose, wheat-straw holocellulose, cellulose and xylan. Applied and Environmental Microbiology 53, (in the Press).

Lowe, S. E., Theodorou, M. K. \& Trinci, A. P. J. $(1987 b)$. Growth and fermentation of an anaerobic 
rumen fungus and the effect of temperature on development. Applied and Enironmental Microbiology 53, (in the Press).

MedofF, G. \& Kobayashi, G. A. (1980). The polyenes. In Antifungal Chemotherapy, pp. 3-33. Edited by D.C.E. Speller. Chichester: Wiley.

Miller, T. L. \& Wolin, M. J. (1974). A serum bottle modification of the Hungate technique for cultivating obligate anaerobes. Applied Microbiology 27. 985-987.

Mountfort, D. O. \& Asher, R. A. (1985). Production and regulation of cellulase by two strains of the rumen anaerobic fungus Neocallimastix frontalis. Applied and Environmental Microbiology 49, 13141322.

Muller, H., Furter, R., Zahner, H. \& Rast, D. M. (1981). Metabolic products of microorganisms. 203. Inhibition of chitisomal chitin synthetase and growth of Mucor rouxii by nikkomycin Z, nikkomycin $\mathrm{X}$, and polyoxin A: a comparison. Archives of Microbiology 130, 195-197.

MunN, E. A., Orpin, C. G. \& Hall, F. J. (1981). Ultrastructural studies of the free zoospore of the rumen phycomycete Neocallimastix frontalis. Journal of General Microbiology 125, 311-323.

ORPIN, C. G. (1975). Studies on the rumen flagellate Neocallimastix frontalis. Journal of General Microbiology 91, 249-262.

ORPIN, C. G. (1977). The occurrence of chitin in the cell walls of the rumen organisms Neocallimastix frontalis, Piromonas communis and Sphaeromonas communis. Journal of General Microbiology 99, 215218.

ORPIN, C. G. \& MUNN, E. A. (1986). Neocallimastix patriciarum sp. nov., a new member of the Neocallimasticaceae inhabiting the rumen of sheep. Transactions of the British Mycological Society 86, 178-181.

Pearce, P. D. \& Bauchop, T. (1985). Glycosidases of the rumen anaerobic fungus Neocallimastix frontalis grown on cellulosic substrates. Applied and Environmental Microbiology 49, 1265-1269.

Sparrow, F. K., JR (1960). Aquatic Phycomycetes, 2nd edn. Ann Arbor: University of Michigan Press.

VAVRA, J. \& JoYon, L. (1966). Étude sur la morphologie, le cycle évolutif et la position systématique de Callimastix cyclopis Weissenberg 1912. Protistologica 2, 5-16.

W ATERHouse, G. M. (1962). The zoospore. Transactions of the British Mycological Society 45, 1-20.

WEBB, J. \& JACKSON, M. B. (1986). A transmission and cryo-scanning electron microscopy study of the formation of aerenchyma (cortical gas-filled space) in adventitious roots of rice (Oryza sativa). Journal of Experimental Botany 37, 832-841.

WeISSENBERG, R. (1912). Callimastix cyclopis, n.g. n.sp. Ein geibeltragendes Protozoon aus dem Serum von Cyclops. Sitzungsberichte der Gesellschaftnaturforschender Freunde zu Berlin 5, 299-305.

WEISSENBERG, R. (1950). The development and affinities of Callimastix cyclopis Weissenberg, a parasitic microorganism from the serum of cyclops. Proceedings of the American Society of Protozoologists 1, 4-5. 